\title{
Pre-hospital care of road traffic accident victims in the Niger Delta: a private initiative and experience
}

This article was published in the following Dove Medical Press journal: Open Access Emergency Medicine

\author{
Abiodun Oyinpreye Jasper' \\ Gladys Chidinma Jasper ${ }^{2}$ \\ Irene Oghenerukevwe \\ $\mathrm{Edah}^{3}$ \\ Courage Akpesiri Edah ${ }^{2}$ \\ 'Department of Anaesthesia, Faculty \\ of Clinical Medicine, College \\ of Health Sciences, Delta State \\ University, Abraka, Delta State, \\ Nigeria; ${ }^{2}$ Department of Anaesthesia \\ and Intensive Care, Treasurehold \\ Specialist Hospital, Sapele, Delta State, \\ Nigeria; ${ }^{3}$ Department of Anaesthesia \\ and Intensive Care, Delta State \\ University Teaching Hospital, Oghara, \\ Delta State, Nigeria
}

\begin{abstract}
This is a review of pre-hospital care of road traffic accident (RTA) victims in the Niger Delta covering the highway linking Benin to Warri in Delta State, Nigeria, from January to December (2017). The non-availability of these services in the South South Nigeria prompted this initiative. Ambulance services with technicians and doctors attended the patients when accidents occurred. This was done in collaboration with the Nigeria Red Cross, Police, Army, and Road safety patrol teams. The information from the patrol team through dedicated lines initiated the emergency response. Response time was an average of 10-30 minutes. A major benefit of this initiative is early commencement of resuscitation and prevention of secondary injuries. A total of 70 RTA victims were salvaged from the accident scene by the Red Cross Society in 2017. A total of 29 RTA patients were salvaged through this initiative in 2017, in Delta State, Nigeria. The main challenges of this effort were delayed communication, insufficient ambulance manpower, and limited funding. Government involvement in public enlightenment, training paramedics, and provision of ambulance services to reduce deaths on our highways is needed.
\end{abstract}

Keywords: pre-hospital care, resuscitation, ambulance, emergency medical services, road traffic accidents, primary injuries, secondary injuries

\section{Introduction}

Modern pre-hospital care evolved from the prototype of the "flying ambulances" by Napoleon's private surgeon, Dominique-Jean Larrey in 1792, where horse-drawn carriages were used as means of moving medical supplies to battlefields and to take away safely the wounded soldiers for medical attention. ${ }^{1}$ Physician-led efforts were started by a German surgeon in Heidelberg by moving the theater to trauma sites. ${ }^{2,3}$ Thereafter, the American paramedic model was established. ${ }^{4-6}$

In Nigeria, the story of EMS evolved from the use of ambulances by undertakers for moving dead bodies: up until early 1990 when Tokaro EMS, an Israeli outfit introduced EMS in Lagos, Nigeria. This venture failed due to low patronage. In 1995, an oil company in the Niger Delta area of Nigeria started EMS on a low scale primarily for rescue operations for their staff. ${ }^{7}$

State governments have in the past made attempts at the running of EMS. Delta State for example sets up a committee to midwife EMS in 2003. The full implementation of this plan however happened in 2009. The emphasis then was on acquisition of state of the art ICU ambulances for land and ambulance boats for the riverine areas. Poor funding, implementation, and inadequate training of staff to run the process contributed in no small way to the inability of the project to self-sustain. Earlier
Jasper

Department of Anaesthesia, Faculty of

Clinical Medicine, College of Health

Sciences, Delta State University, Abraka,

PO Box 1737, Effurun, Delta State,

Nigeria

Email aojasper@yahoo.com 
efforts were made by Lagos and Rivers States in 2001 and 2002, respectively. Other states have since followed suite in establishing Emergency response services.

\section{Purpose of this pre-hospital care initiative}

This is a review of pre-hospital care of RTA victims in the Niger Delta covering the highway linking Benin to Warri in Delta State Nigeria over a period of 1 year (2017). The initiative was derived from the need to make up for the deficits in pre-hospital care and to augment already existing services.

In South Africa, there is an organized public and private system where accident and emergency services are provided with ambulance services, and prompt services are rendered at designated hospitals with a regional and national spread. ${ }^{8}$

With the purpose of saving lives on our roads, ambulances and EMS were set up by this private initiative, to further stem the tide of carnage on our roads and also support government efforts. The efforts both at the national and state levels have proven to be insufficient to meet this urgent need.

A bill was sent to the National Assembly by the Minister of Health Professor Isaac Adewole, and a master plan for regulation of training of paramedics and pre-hospital care was developed. These current efforts though laudable require a widespread and detailed implementation. There is an obvious deficit in this effort in the South South Nigeria. ${ }^{9}$

\section{Setting up pre-hospital care}

Most EMS adopt multiple-level approaches where basic medical staff get to the scene first, followed up quickly by more skilled medical personnel. The advance team is trained to perform basic cardiopulmonary resuscitation, defibrillation, and basic airway management. Advanced airway management and resuscitation follow on the arrival of skilled paramedics or physicians. Countries adopt models convenient for them. France and Germany for example use a system where the physician is brought to the patient. In the USA, a paramedic model holds sway. We adopted a mixture of different models depending on the need and severity of the prevailing circumstance and availability of staff. ${ }^{9-11}$

Our manned ambulances worked in collaboration with Police, Army, and Road safety patrol teams. The information from the patrol team through dedicated lines initiated the emergency response to dedicated hospitals.

Extrication of victims from Wreckage required training to avoid complications. When called upon, the team supervised such procedures with the help of police and road safety, who coordinated an orderly and safe extrication process, because sometimes, an overenthusiastic crowd does more harm.
Resuscitation starts immediately after the arrival of the team that comprises usually a doctor, sometimes, two, nurses, and technicians or paramedics.

Salvage by fellow commuters, especially commercial transporters, happened occasionally. For the fear of being accused of being responsible for the accident or death of victims, some would rather inform the police on their way and not be directly involved. Hopefully, with the passage of the Good Samaritan law, we may see a change of attitude in this regard. ${ }^{12}$ This also applies to villagers at the accident scene who may be first responders and may be helpful in initiating emergency response. In the recent past, the Nigerian Red Cross had conducted series of first responders' training in accident-prone areas and those prone to crisis in Delta State. Efforts are underway to familiarize these villagers with our numbers. Also, the Good Samaritan law in the House of Assembly would go a long way to help protect persons at the site of accident who may help before the arrival of the police or road safety officials.

In a study by Solagberu et al, ${ }^{13}$ the following three categories of persons brought victims to ER: EL 1,081, 52.83\%; P/F 827, 40.42\%; and BS 138, 6.74\%. Gladly, these security agencies are stationed a few kilometers apart and serve the vital role of early initiation of emergency response. In a review of the activities of Lagos state ambulance services between 2001 and 2006, RTAs were responsible for the highest number of emergencies $(35 \%)$. This was followed by crowd accidents, $32.2 \%$; gas/bomb explosions, $8.8 \%$; and domestic accidents, $0.1 \%$. A total of 32,774 cases were seen during the 5 -year study period with an annual average of 5,462 and 15 patients per day. Of whom, 21,977 (67.1\%) were male and $10,797(32.9 \%)$ female, giving a male to female ratio of 2.04:1. ${ }^{14}$

Figures from Delta state where we operate show that a total of 70 RTA victims were salvaged from the accident scene by the Red Cross society in 2017. A total of 29 RTA patients were salvaged through this initiative in 2017, in delta state Nigeria along the Benin-Warri highway.

For fellow road users, the availability of signposts with emergency numbers inscribed was useful to initiate the process. These numbers are being made available on Television, radio stations, and Internet platforms to create the necessary awareness. Priority lines were provided by mobile telephone companies for easy access and recall. In order to meet up with the golden hour or platinum time, efforts are being made to intensify the training of police, road safety, commercial road users, and some villagers living along the express to function as first responders. In the study by Solagberu et al, the $\mathrm{P} / \mathrm{F}$ 
responsible for only $40 \%$ of transport should be trained and equipped to offer BTLS. ${ }^{13}$

\section{Response time}

While response time was an average of 10-30 minutes, ambulance team was able to salvage patients to a referral hospital for definitive treatment. A major benefit of this initiative is early commencement of resuscitation at the accident scene and in transit with the added benefit of the prevention of secondary injuries. This is a complete departure from the former practice where response can last from hours to days depending on the terrain involved. Sensitization of the public and fellow commuters who are encouraged to help "save a life" has helped to reduce response time to safe levels. Other low- or middle-income African countries where pre-hospital care is nonexistent suggest average hospital arrival times of 93.6 minutes as in the study by Oluwadiya et al. ${ }^{15}$

Unlike in Nigeria where there is no official response time benchmark, in South Africa a period of 15 minutes seems to be acceptable. Forty minutes is considered adequate in rural areas. In the Netherlands, the standard time is 15 minutes, which is met by $95 \%$ of the time. ${ }^{16}$ In the UK category, the response time for life-threatening situations is 8 minutes. Ambulances target making at least $75 \%$ compliance in England and $65 \%$ in Wales. In the US, there are variations. These differ from state to state. A range of 10-15 minutes is considered acceptable depending on the state, although 8 minutes in $95 \%$ of the time is considered standard. The reality on ground shows that with increased calls and inadequate funding and personnel, this time is often not met, although the current research questions the validity of this standard. ${ }^{17,18}$

In our environment, delayed response is minimized by training of first responders in local communities on these highways. Training of commuters, military, police, and road safety patrol teams is an all-inclusive approach that we are adopting. We are also setting up makeshift ambulance bays on the highways to facilitate quicker response.

\section{Vehicle type}

In a regional study by Oluwadiya et al, ${ }^{15}$ only 160 of the 1,996 patients who presented at the accident and emergency were transported to hospital in an ambulance; none of whom had any form of pre-hospital care, which seemed to be the pattern in most African countries.

Vehicular transport for accident victims differs from country to country. In our case, we started this project with an intensive care ambulance. However, with more experience on the field and with increasing demands in face of limited resource we see the wisdom in appropriate means and less expensive means of transport. Vans with open backs and tricycles are used depending on the type of injury. While vital resources are channeled to training of personnel and first responders and quick movement of victims to appropriate hospitals, the ICU ambulance (Figures 1A,B and 2A,B) is then reserved for critically ill patients needing advance care.

We are also aware that an ambulance without resuscitation kits and manpower is not better than a private vehicle, since no resuscitation is likely to take place between the accident scene and the hospital. Less optimal options available are pickups, busses, and Hilux jeeps, sometimes used by the police and road safety corpse and other road commuters. These vehicles are owned by individuals or volunteers for transport of accident victims to the hospital. These volunteers who happen to be at the scene of accident may or may not have knowledge of basic resuscitation or extrication, but are guided by medical staff or road safety or police officers with some basic training.

Vehicles used in South Africa range from small to large and new to very old vehicles driven by local resources.

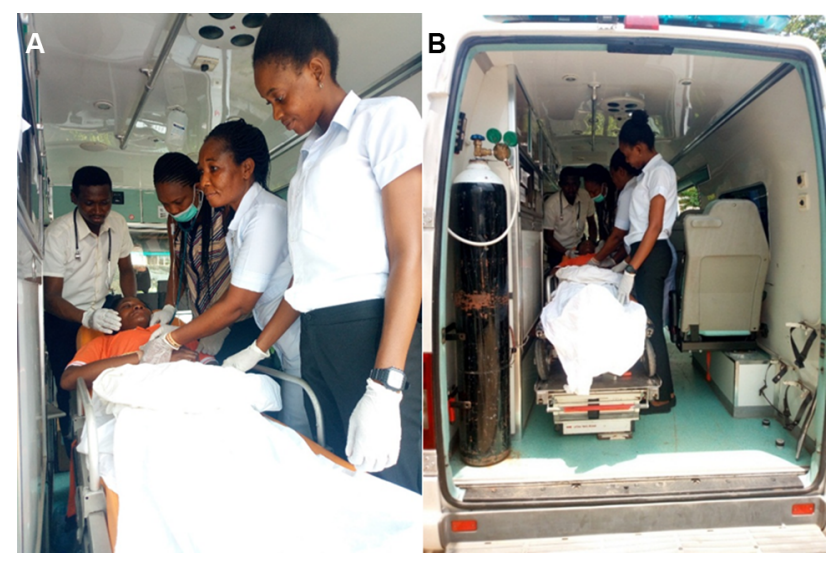

Figure I Rescue team: close up view (A), external view (B).

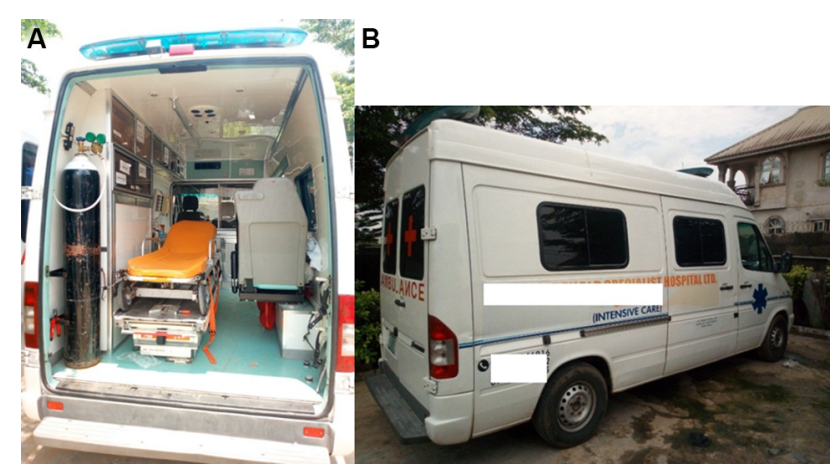

Figure 2 Intensive care ambulance: internal view (A), external view (B). 
There is no specific design, although some of the vehicles comply with European and American standards defined by the KKK-1822 standards requirement. ${ }^{19,20}$ The Dutch mandates all ambulances to meet the set criteria established by Netherlands Ambulance Institute and European standards published by the European committee for standards that specify types of vehicles and equipment. Dutch paramedics use ALS-equipped motorcycles in areas prone to traffic congestion for rapid response. ${ }^{21}$

\section{Transportation}

Multiple modes of transport in our environment can be used in mass casualty, after a proper triage has been done allocating the safest mode of transport for each patient. These include ICU ambulances (Figures 1A,B and 2A,B) equipped for resuscitation and smaller vans. "keke" tricycles could be good for ease of transportation but could be dangerous for a spinal cord-injured patient. Boats (Figure 3), private cars, and Hilux jeeps are other alternatives, depending on the terrain. Helicopters and air ambulances are engaged under special arrangements, when REL of accident victims request for transfers to more specialized centers from receiving hospitals. While we work toward improving our services, it

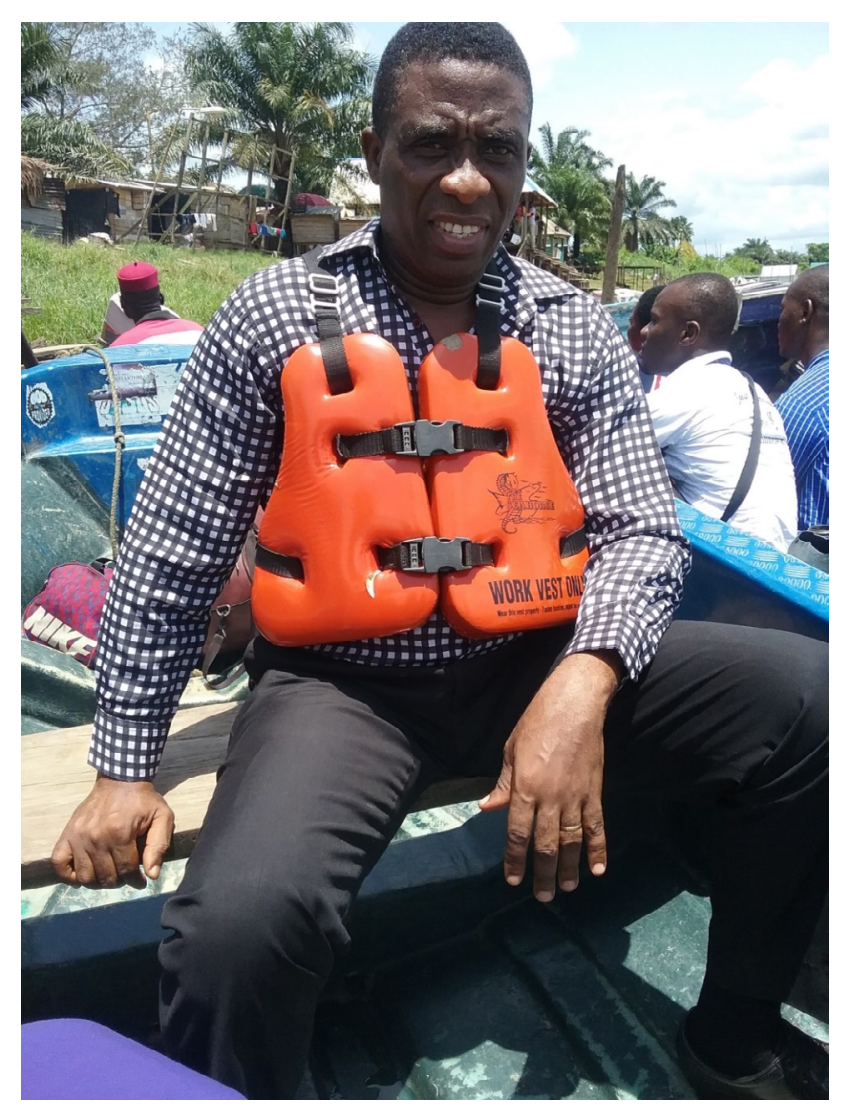

Figure 3 Boat rescue mission team member. is noteworthy that the South African land and air ambulance services are worth emulating. ${ }^{22}$

\section{Manpower}

We operate a physician-led EMS system that helps us to initiate early resuscitation and airway protection. Team is led by a physician anesthetist. Airway compromise is known to be the earliest cause of death in transit from the accident scene to the referral hospital. It is second to massive hemorrhage at the scene of accident, eg, ruptured aorta. When the team is overwhelmed, help is sought from sister institution to send personnel and be prepared to receive the victims.

We practice a mixture of the French and American EMS structure. While the Americans operate a purely paramedic system and quick transportation to the referral hospital, the French operates a physician-led system where resuscitation takes place, sometimes for prolonged periods at the scene of accident. ${ }^{9-11}$ For us, availability of personnel, equipment for resuscitation, and proximity to the referral hospital determine which approach we adopted.

\section{Triage and patient transfer}

On arrival at accident scenes, quick triage is done with resuscitation with airway maintenance and protection, intravenous cannulation, applying tourniquet, and pressure bandages. Spine protection is ensured with conventional spine boards or sometimes improvised. These measures are taken and followed up quickly with patient transfer. Our vehicles or other available and suitable ones can be used for this purpose. Volunteers are very helpful at these stages. Sometimes it may be fellow road commuters. Well relations can play vital roles at this stage, when they have been screened and deemed fit to do so by the attending physician

Efforts are made to transfer patients promptly and we strive to keep our transfer and arrival time at the referral hospital within 20-30 minutes, after triage with ongoing resuscitation in transit.

\section{Health facilities}

In France, hospitals that handle these patients must have an emergency department and a minimum of two operating theaters. ${ }^{23}$ The attending teams are physician led. These centers must also have subspecialties to take care of the trauma patient. These standards are worthy of emulation.

The health facilities of choice in our immediate environment are those with tertiary specialist facilities, such as Delta State University Teaching Hospital and Treasurehold Specialist Hospital. Both centers have neurosurgical, 
orthopedic, Emergency Medicine, Anesthesia, and intensive care facilities for prompt definitive care. The radiological diagnostic facilities at the teaching hospital are an asset in this regard. Temporary waivers are granted for these investigations to fast-track the care of these trauma patients. This kind of cooperation between governments and private outfits has helped to ease the burden of the care of these patients.

This has also helped to facilitate transfer of patients for diagnostic investigations such as $\mathrm{CT}$ scan after resuscitation and stabilization with the use of intensive team and ambulances. Interhospital referral is also done in this manner.

\section{Training}

Staff and crew are BLS certified nurses and technicians with a few others who are ACLS certified. The team is usually led by a trained anesthetist with a postgraduate diploma in anesthesiology. BLS courses are done by an AHA-certified trainer, which also oversees the output of staff from time to time. Efforts are being made to undertake ATLS training for physician staff. Where the team is not accompanied by a physician anesthetist, they operate under the cover of their medical director's license of practice.

First responders' course is also given to police and road safety officers who may do minimum resuscitation while activating emergency response. This includes a course on extrication and BLS. An incident that happened in Nigeria, in April 2016, in which six medical doctors traveling to a conference lost their lives in a bus accident is quite instructive. Federal Road Safety officers who responded to the distress call were not trained as first responders. They moved the victims in a van to a nearby hospital. Lack of training and possibly absence of resuscitation equipment may have resulted in more deaths: going by eye witness accounts among the surviving doctors.

It is noteworthy that the Red Cross organizes regular first responders' course for communities in Delta that are prone to conflict and trauma, including those along the highways. These programs are sponsored by the international Red Cross society. The Australasian Registry of EMTs has also been opened in Nigeria especially for fast track-training programs for experienced nurses, doctors, and health scientists. These are aimed at supporting existing personnel until the paramedics initiated by the federal government become available. ${ }^{24,25}$

In South Africa, training programs are conducted for BAA courses. A 2-year medical emergency degree was also developed to maintain the supply of trained personnel for these services. ${ }^{18}$ However, in Nigeria paramedic schools are being set up to fill this gap.

\section{Finance}

The program is designed to be self-sustaining. While accident victims are transported free from the scene of accidents, their treatment at the referral hospital is borne by patients and REL. No cost is spared at resuscitation, but definitive treatment for example craniotomy in the head injured is paid for. Where REL have some means they are made to pay a fee for ambulance transport. We adopt a means whereby the rich pays for the poor at our hospitals where urgent definitive care is given to the victims on arrival of the REL. This is even crucial in our funding process in the absence of reliable and functional health insurance scheme.

The cost of training of personnel is borne by the hospital. With the cost benefit of improved output in prompt and appropriate care of accident victims, the crew gets their salaries from the hospital and extra allowances for such movements.

When we have unidentified victims, treatment continues while efforts are made to reach out to the REL. Presently, we have just one ICU ambulance, and we look forward to procuring less sophisticated ambulances as the burden of this task increases. Concerted efforts are underway to increase collaboration with other stakeholders in this initiative. Sharing the burden with non-governmental organizations such as the Red Cross and other government agencies in the Niger Delta has gone a long way in meeting up with minimum benchmarks in the care of these patients.

In France, where most people are health insured, they run universal Health policy; ambulance services charge fee for service. Sixty-five percentage of cost is funded by government insurance, while private insurance of patient's choice covers the balance $35 \%$. Sometimes, especially in low-priority calls, payments can be made in advance. Arrangements are thereafter made for those victims that are health insured to be reimbursed by the insurance companies (public and private). By law, all accident victims who treated regardless of their ability to pay. Other countries have different funding models that suite them. ${ }^{26}$

\section{Conclusion}

The main challenges of this effort were delayed communication (poor network), insufficient ambulance manpower, and limited resources to cater for the accident victims. We recommend more government involvement in training of paramedics and provision of ambulance services on our highways to mitigate this scourge of accidents on our highways. 


\section{Abbreviations}

ACLS, advanced cardiac life support; ALS, advanced life support; AHA, American Heart Association; BAA, Basbasic ambulance assistance; BLS, basic life support; BS, bystanders; BTLS, basic trauma life support; CT, computerized tomography; EMS, emergency medical services; ER, emergency room; ICU, intensive care unit; P/F, Police/Federal Road Safety Corps; REL, relatives; RTA, road traffic accident.

\section{Consent for images}

The people in the images have provided written informed consent for the images to be published.

\section{Disclosure}

The authors report no conflicts of interests in this work.

\section{References}

1. Williamson K, Ramesh R, GrabinskyA. Advances in prehospital trauma care. Int J Crit Ill Inj Sci. 2011;1(1):44-50.

2. Mahler W. Der Operationswagen der Chirurgische Universitätsklinik Heidelberg [Surgical operations at University Hospital Heidelberg]. Chirurg. 1960;9:421-423. German.

3. Herzog W. 40 Jahre moderner Rettungsdienst-Gummersbacher Modell [40 years modern rescue service Gummersbacher model]. Der Notarzt. 1999;15:37-41. German.

4. Pantridge JF, Geddes JS. A mobile intensive-care unit in the management of myocardial infarction. Lancet. 1967;290(7510):271-273.

5. Lewis RP, Fulkerson PK, Stang JM, Sampson KL, Dutko HJ. The Columbus emergency Medical service system. Ohio State Med J. 1979;75(6): 391-394.

6. Criley JM, Lewis AJ, Ailshie GE. Mobile emergency care units. implementation and justification. Adv Cardiol. 1975;15:9-24.

7. National Emergency Department Inventories. Emergency Medical Network; 2017. Available from: www.emnet-nedi.org. Accessed January 29, 2019.

8. MacFarlane C, van Loggerenberg C, Kloeck W. International EMS systems in South Africa: past, present, and future. Resuscitation. 2005;64(2):145-148.

9. Adnet F, Lapostolle F. International EMS systems: France. Resuscitation. 2004;63(1):7-9.

10. Roessler M. Zuzan O. EMS systems in Germany. Resuscitation. 2006;68:45-49.
11. Langhelle A, Lossius HM, Silfvast T, et al. International EMS systems: the Nordic countries. Resuscitation. 2004;61(1):9-21.

12. Razzak JA, Kellermann AL, Arthur L. Emergency medical care in developing countries: is it worthwhile? Bull World Health Organ. 2002;80(11):900-905.

13. Solagberu B, Ofoegbu C, Abdur-Rahman L, et al. Pre-hospital care in Nigeria: a country without emergency medical services. Niger J Clin Pract. 2009:1229-1233.

14. Adewole OA, Fadeyibi IO, Kayode MO, et al. Ambulance services of lagos state, Nigeria: a six-year (2001-2006) audit. West Afr J Med. 2012;31(1):3-7.

15. Oluwadiya KS, Olakulehin AO, Olatoke SA, Kolawole IK, Olasinde AA, Komolafe EOK. Association for the Advancement of Automotive Medicine 49th Annual Proceedings; Boston, MA, USA; September 12-14, 2005. Des Plaines, IL: Association for the Advancement of Automotive Medicine; 2005.

16. Macfarlane C, Loggerenberg Cvan, Kloeck W. International EMS systems in South Africa: past, present, and future. Resuscitation. 2005;64(2):145-148.

17. Wulterkens D (2005-12-06). EMS in the Netherlands: A Dutch Treat? J Emerg Med Serv. Epub 2005 Dec 5.

18. Pons PT, Markovchick VJ. Eight minutes or less: does the ambulance response time guideline impact trauma patient outcome? J Emerg Med. 2002;23(1):43-48.

19. No authors listed. Emergency medical services in the United Kingdom. Available from: https://en.wikipedia.org/wiki/Emergency_medical_services_in_the_United_Kingdom. Accessed April 25, 2018.

20. U.S. General Services Administration [homepage]. Available at: https:// www.gsa.gov/. Accessed April 25, 2018.

21. No authors listed. Emergency medical services in Hong Kong. Available at: http://www.bowincars.org/mediawiki-1.6.12/extensions/Fetch. php?topic=Emergency_medical_services_in_Hong_Kong. Accessed April 25, 2018

22. No authors listed. Emergency medical services in South Africa. Available at: https://en.wikipedia.org/wiki/Emergency_medical_services_in_South_Africa. Accessed April 24, 2018.

23. Burstein H. Pre Hospital Care in Europe. Disaster Medicine Lippincott Ed. Fairhurst R (November 2005). 2007:137-138.

24. Nnamdi N. Improving Care \& Response in Nigeria. J Emerg Med Serv. Epub 2017 May 31.

25. Ojomoyela R, Ogundipe S, Obinna C. How 6 Ekiti doctors died, survivor recounts; 2016. Vanguard News. 2017. Available from: 2016 www. vanguardngr.com/2016/04/6-ekiti-doctors-died-survivor-recounts/. Accessed May 3, 2017.

26. National Coalition on Health Care [homepage]. Available at: https:// nchc.org. Accessed September 19, 2008.
Open Access Emergency Medicine

\section{Publish your work in this journal}

The Open Access Emergency Medicine is an international, peerreviewed, open access journal publishing original research, reports, editorials, reviews and commentaries on all aspects of emergency medicine. The manuscript management system is completely online and includes a very quick and fair peer-review system, which is all
Dovepress

easy to use. Visit http://www.dovepress.com/testimonials.php to read real quotes from published authors. 